\title{
P02.122. Mindfulness meditation for pediatric chronic pain: effects and precautions
}

\author{
B Golianu ${ }^{1 *}$, L Waelde ${ }^{2}$ \\ From International Research Congress on Integrative Medicine and Health 2012 \\ Portland, Oregon, USA. 15-18 May 2012
}

\section{Purpose}

Although there is a substantial literature about the effectiveness of psychological therapies such as relaxation for pediatric chronic pain and about mindfulness meditation (MM) for health and mental health conditions, there has been little systematic attention to the use of MM for pediatric chronic pain. This presentation will address lessons learned from our ongoing clinical trial of MM in a pediatric chronic pain service at a university clinic.

\section{Methods}

We present case material from our ongoing pilot clinical trial of a manualized mindfulness meditation intervention, called Inner Resources for Coping with Chronic Pain (Waelde, 2011). Participants are 30 patients diagnosed with chronic pain and aged $11-17$ receiving a 6-week, group-based meditation intervention that includes daily home practice of the techniques. Case material from two participants will be presented to illustrate effects and precautions.

\section{Results}

Our case material indicates that patients are able to learn and practice the MM techniques, with good adherence to the home practice. A male patient with multiple pain complaints was able to learn and practice the meditation techniques and use them to cope with stressors associated with his medical conditions. A 16 year old female patient with longstanding participation in pain management that primarily involved distraction found the concurrent use of mindfulness and distraction to be confusing and ineffective.

\section{Conclusion}

MM shows promise as an intervention for helping children and adolescents to deal with chronic pain. The children and adolescents in our clinical trial have evidenced the ability to engage with the material and adhere to regular home practice of the techniques and application of them to presenting problems. However, a note of caution is raised by the possible incompatibility of mindfulness with concurrent therapies emphasizing the use of distraction for dealing with chronic pain.

\section{Author details}

${ }^{1}$ Stanford University Medical Center, San Carlos, USA. ${ }^{2}$ Palo Alto University, Palo Alto, USA.

Published: 12 June 2012

\section{doi:10.1186/1472-6882-12-S1-P178}

Cite this article as: Golianu and Waelde: P02.122. Mindfulness

meditation for pediatric chronic pain: effects and precautions. BMC Complementary and Alternative Medicine 2012 12(Suppl 1):P178.

Submit your next manuscript to BioMed Central and take full advantage of:

- Convenient online submission

- Thorough peer review

- No space constraints or color figure charges

- Immediate publication on acceptance

- Inclusion in PubMed, CAS, Scopus and Google Scholar

- Research which is freely available for redistribution

${ }^{1}$ Stanford University Medical Center, San Carlos, USA

Full list of author information is available at the end of the article 